\title{
Políticas de promoción sectorial en Argentina: el caso de las plantaciones forestales y la conformación del sector forestoindustrial
}

Sectoral policies in Argentina: the case of forest plantations and the shaping offorest-based industries

\author{
Martín Aguerre \\ Ingeniero forestal, Profesor del curso \\ Economía y Legislación Forestal \\ (Departamento de Desarrollo Rural, \\ FCAyF, UNLP), Investigador de la \\ Unidad Promocional de Investigación \\ y Desarrollo PyDEF (Políticas y \\ Desarrollo Forestal), FCAyF, UNLP. \\ martinraguerre@gmail.com
}

\section{Gerardo Denegri}

Ingeniero forestal y Magister en Economía del Medio Ambiente y Rec. Naturales, Profesor del curso Economía y Legislación Forestal (Departamento de Desarrollo Rural, FCAyF, UNLP), Investigador de la Unidad Promocional de Investigación y Desarrollo PyDEF (Políticas y Desarrollo Forestal), FCAyF, UNLP. gdenegri@agro.unlp.edu.ar

\section{Gustavo Acciaresi}

Ingeniero forestal, Profesor del curso Introducción a la Administración (Departamento de Desarrollo Rural, FCAyF, UNLP), Investigador de la Unidad Promocional de Investigación y Desarrollo PyDEF (Políticas y Desarrollo Forestal), FCAyF, UNLP. gaccia@agro.unlp.edu.ar

\section{Resumen}

Desde mediados del siglo XX (Ley 13273) a la fecha, Argentina alcanzó 1.300.000 hectáreas de plantaciones forestales, que abastecen más del 90\% de la demanda industrial. El objetivo general del trabajo es analizar la evolución del sector forestal en el marco de la política estatal de promoción de las plantaciones en Argentina. Se caracterizan los instrumentos de promoción aplicados hasta la fecha y se compara el desarrollo forestoindustrial argentino con respecto a Brasil, Chile y Uruguay. Ante el vencimiento del régimen de promoción vigente (Ley 26432), se propone la implementación de nuevos mecanismos de promoción diferenciados por región con potencial forestal según el destino de las plantaciones (industrial, servicios ambientales o una combinación de ellos).

Palabras clave: desarrollo - promoción - plantaciones - forestoindustria - planificación 
Fecha de recepción:

26.3.18

Fecha de aceptación:

25.7.18

\begin{abstract}
Since the middle of the twentieth century (law 13273) to date, Argentina reached 1.3 million hectares of forest plantations, which supply more than $90 \%$ of the industrial demand. The general objective of the present article is to analyze the evolution of the forestry sector within the framework of the State policy of promotion of plantations in Argentina. In addition to the characterization of the promotional instruments implemented to date, a comparative analysis of the development of Argentina's primary and secondary forestry sector vis-à-vis to that of Brazil, Chile and Uruguay. In view of the expiration of the Promotion Law (26432), we propose the implementation of new promotional mechanisms differentiated by region with forest potential according to the destination of the plantations (industries, environmental services or a combination of them).
\end{abstract}

Key words: development - promotion - afforestation forest industries - planification

\section{Introducción}

La importancia del sector forestal en la Argentina y el mundo se evidencia al señalar que el comercio mundial de productos de la madera crece a una tasa promedio del 3,5\% anual e intercambia montos del orden de los USD 380.000 millones, superando en su magnitud al de cereales y oleaginosas (Schlichter et al., 2012), en un marco de "sustitución progresiva de la materia prima proveniente de bosques nativos por maderas provenientes de bosques implantados". El crecimiento demográfico, el desarrollo de la demanda de los países llamados "emergentes", los compromisos internacionales derivados del cambio climático y las acciones de mitigación acordadas explican buena parte de este proceso.

Argentina dispone de diferentes tipos de bosques nativos y cultivados y otros tipos de tierras forestales cuya superficie es de aproximadamente 27.000.000 de hectáreas, brindando diversos servicios ambientales, entendidos como "aquellas funciones de los ecosistemas que generan beneficios y bienestar para las personas y la comunidad" (Hueting et al., 1998). Entre ellos se pueden mencionar: la regulación del clima, el mantenimiento de la biodiversidad, la protección de cuencas hídricas, la conservación del suelo, la provisión de agua, el almacenamiento y secuestro de carbono, su empleo como espacios de descanso 
y recreación, entre los más relevantes. En Argentina, una amenaza a estas funciones de los bosques está dada por la presión de cambio de uso del suelo, no obstante el avance que significó la sanción en 2007 de la Ley 26331 sobre "Presupuestos mínimos de protección ambiental de bosques nativos". Esta ley obliga a las provincias a realizar y actualizar periódicamente un ordenamiento territorial de sus bosques nativos, estableciendo tres categorías de uso para las tierras boscosas: conservación (zonas rojas), uso sustentable del bosque (zonas amarillas) y aquellas susceptibles de cambiar su uso (zonas verdes).

Las principales regiones que concentran a las formaciones nativas son: Parque Chaqueño, Selva Misionera, Selva Tucumano-Boliviana, Bosque Andino Patagónico, Espinal y Monte. En general, en todos los biomas ${ }^{1}$ predominan las latifoliadas y especies de madera dura; es escasa la presencia de coníferas. Esta conformación fue determinante para la necesidad de desarrollar plantaciones debido a la tecnología de industrialización existente en la primera mitad del siglo XX, dirigida al uso de materia prima proveniente de coníferas.

Por otra parte, desde mediados del siglo XX Argentina ha desarrollado una superficie de plantaciones forestales del orden de un millón trescientas mil hectáreas (estimación propia realizada en base a datos actualizados a julio de 2018 provenientes de la página de la Subsecretaría de Desarrollo Forestoindustrial, Ministerio de Agroindustria, fuente: https://datos.agroindustria.gob.ar/dataset/inventario-nacional-de-plantaciones-forestales-por-superficie). Estas masas forestales abastecen más del 90\% de la demanda de materia prima de la industria y están conformados casi exclusivamente por especies exóticas de rápido crecimiento. Específicamente, se componen principalmente por coníferas (pinos), seguidas por eucaliptos y salicáceas (álamos y sauces). Las plantaciones que se concentran mayoritariamente en la Mesopotamia (Misiones, Corrientes y Entre Ríos), Delta del Río Paraná, y provincias de Buenos Aires, Córdoba y Neuquén, permitieron reducir la presión de extracción maderera sobre el bosque nativo (figura 1). 
Figura 1. Ubicación de plantaciones forestales en Argentina (2018).

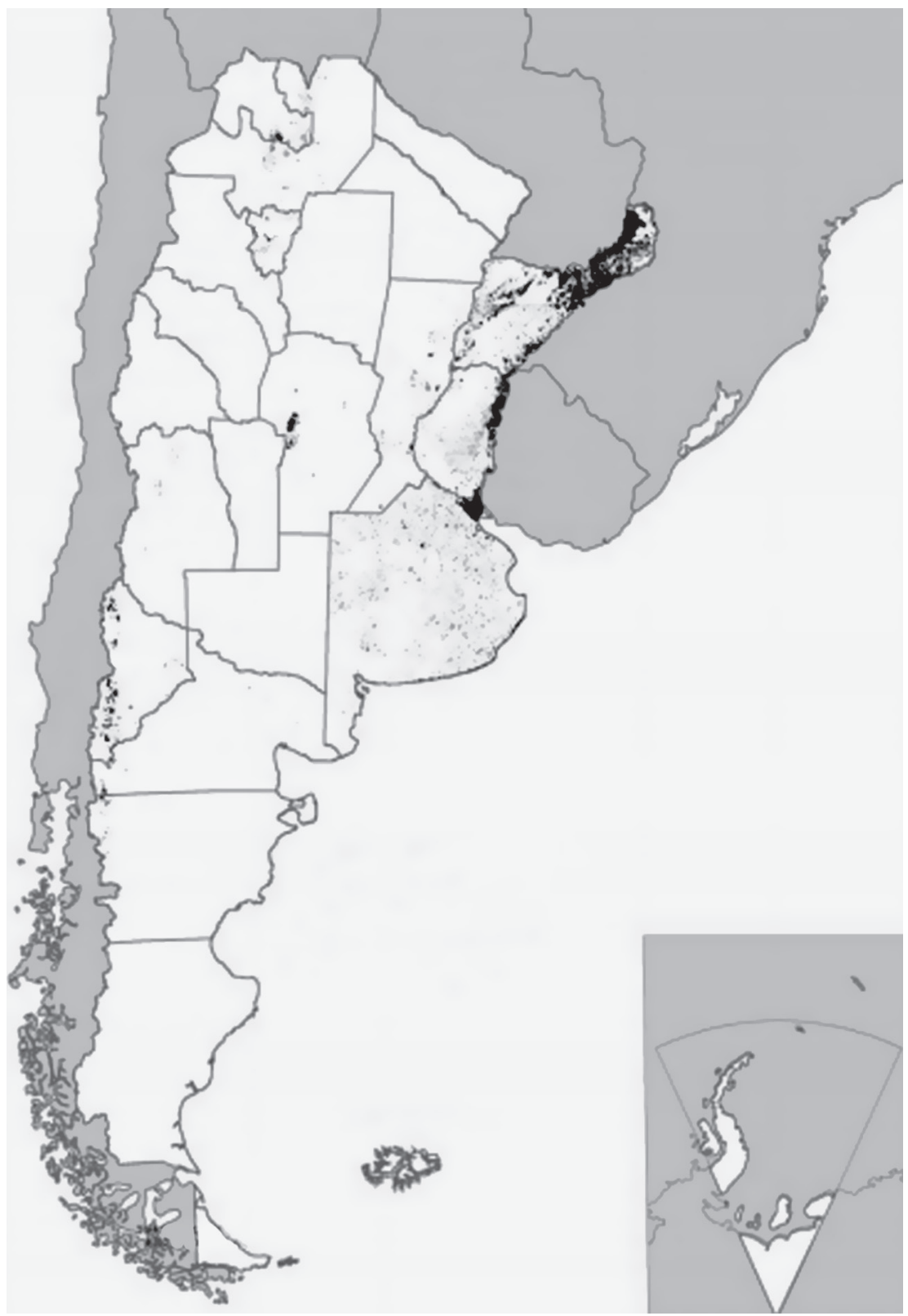

Fuente: Ministerio de Agroindustria de la Nación, Subsecretaría de Desarrollo Foresto Industrial (http://ide.agroindustria.gob.ar/visor/?v=forestal) 
Las plantaciones forestales se definen como cultivos con especies arbóreas que generan ecosistemas forestales constituidos a partir de la intervención humana, mediante la instalación de una o más especies, nativas o introducidas; se realizan con fines de producción de madera u otros productos forestales, provisión de servicios ambientales o cualquier otra combinación de los anteriores (SERFOR, 2018). Para este trabajo se restringe esta definición a los cultivos cuyo principal objetivo es la provisión de madera para su industrialización. La generación de esta masa forestal no se produjo de manera espontánea por la sola evolución del mercado, sino que respondió a las políticas implementadas por el Estado Nacional a lo largo de casi 70 años, política sectorial que también se aplicó en forma contemporánea en Brasil, Chile y en Uruguay, a partir de la década de 1990 (Prado Donoso, 2015).

La promoción de las plantaciones forestales se encuentra regida en la actualidad en Argentina por la Ley 26432, promulgada el 18 de diciembre de 2008, norma que en su artículo segundo establece la prórroga por diez años del régimen de incentivos a las plantaciones de la Ley 25.080 (sancionada el 16 de diciembre de 1998). Esta norma en cuestiones ambientales se subordina a la Ley 26331 con el fin de evitar que el beneficio económico no reintegrable para el desarrollo de plantaciones forestales se utilice para financiar la reconversión de bosques nativos en plantaciones, práctica muy común en las décadas de 1960 y 1970. Esta política de intervención estatal, gestada en la década de 1940, debe adecuarse al actual siglo que presenta oportunidades, amenazas y desafios en los planos social, económico y ambiental, y adaptarse a los actuales contextos internacional y nacional.

Efectivamente, los bosques nativos y plantaciones forestales son concebidos en la actualidad como generadores de una amplia gama de bienes y servicios ambientales; dada su importancia, se exige a los diferentes niveles del Estado un replanteo de los paradigmas de intervención. Un punto relevante de esta discusión es determinar si se alcanzaron los objetivos planteados cuando se inició la promoción forestal y cuales deberían ser los criterios a incluir en el nuevo instrumento legal a aplicarse en el futuro, luego del vencimiento de la Ley 26432 en diciembre de 2018.

Abordar estas situaciones es una decisión de la sociedad que se instrumenta a través de políticas públicas, definidas para este trabajo como un proceso complejo de interacciones múltiples, estructuradas en modo intencional y causal, que se orienta a alcanzar objetivos considerados de valor para la sociedad o a resolver problemas cuya solución se considera de interés o beneficio público (AguilarVillanueva, 2009).

Entre las políticas públicas se encuentran las que afectan a sectores específicos. Se define, entonces, como política forestal, a "un acuerdo negociado entre el gobierno y otras partes interesadas acerca de una visión compartida para los bosques". En ella se establecen los objetivos relacionados con la ordenación y el aprovechamiento de los bosques y 
árboles y se esbozan las estrategias para alcanzarlos. Las políticas forestales eficaces atienden las necesidades de la sociedad y las metas de desarrollo al tiempo que equilibran los diferentes intereses de las partes, muchos de los cuales trascienden los distintos sectores (FAO, 2010). Se puede afirmar que no existió en Argentina una política forestal explícita, expresada en una declaración o documento formal. Desde esa óptica, se considera que la política forestal argentina es una política implícita que se expresó a través de leyes y regulaciones, así como en el conjunto de programas, proyectos y actividades de las instituciones públicas con la colaboración de los actores sectoriales privados (FAO, op cit).

El objetivo general de este trabajo es analizar la evolución histórica del sector de las plantaciones forestales en el marco de la política de promoción sectorial del Estado Nacional. Los objetivos específicos son la identificación y caracterización de los instrumentos de promoción de las plantaciones forestales comerciales desde la sanción de la Ley13273 hasta la actualidad, comparar el desarrollo del sector forestoindustrial argentino con respecto al experimentado por los mismos sectores en Brasil, Chile y Uruguay y explorar los ejes centrales de los nuevos instrumentos de promoción ante el vencimiento de la Ley 26432 (satisfacción de la demanda del mercado interno o propiciar el desarrollo de una estrategia exportadora).

La hipótesis de este trabajo es la siguiente: los diversos instrumentos de promoción implementados desde 1949 permitieron acumular una superficie forestal suficiente para lograr el autoabastecimiento del complejo celulósico papelero y de productos generados por transformación mecánica.

\section{Materiales y métodos}

La presente investigación se enmarca en el paradigma interpretativo, cuyo supuesto básico es la necesidad de comprender el sentido de la acción social en el contexto del mundo de la vida y desde la perspectiva de los participantes, adoptando el formato de investigación cualitativa. Las metodologías cualitativas suponen y realizan los presupuestos del paradigma interpretativo. Los métodos utilizados son el estudio de caso o casos, la teoría fundada, la historia, la biografia, la investigación acción, observación, análisis de documento y de contenido de texto, técnicas visuales y la entrevista abierta (Vasilachis, 1992).

Entre las principales estrategias para producir datos en la investigación cualitativa se encuentran la entrevista semi-estructurada y en profundidad y entre las fuentes secundarias: textos, documentos y otras publicaciones (Sautu, 2005). Para este trabajo la información primaria se recolectó mediante cuestionarios y entrevistas semiestructuradas a treinta informantes calificados que trabajaron en diversos aspectos de las leyes de fomento forestal y la asistencia a talleres y eventos ligados al tema realizados en las principales regiones forestales de Argentina. La muestra se considera suficientemente 
representativa de la población objetivo, de acuerdo a las organizaciones donde pertenecieron los informantes calificados, según se detalla seguidamente (figura 2):

- Estatales: técnicos que trabajaron en la década de 1980 en el disuelto Instituto Forestal Nacional, la Dirección Nacional Desarrollo Foresto Industrial y las provincias de Misiones, Corrientes y Buenos Aires. - Organizaciones gremiales: responsables de área y miembros de la Asociación Forestal Argentina (AFOA) y de la Federación Argentina de la Industria Maderera y Afines (FAIMA).

- Sector privado: técnicos forestales encargados de plantaciones, aserraderos y establecimientos celulósicos; directivos de empresa foresto industriales (básicamente en la región del NEA) y consultores privados.

Figura 2. Composición de la muestra de actores entrevistados

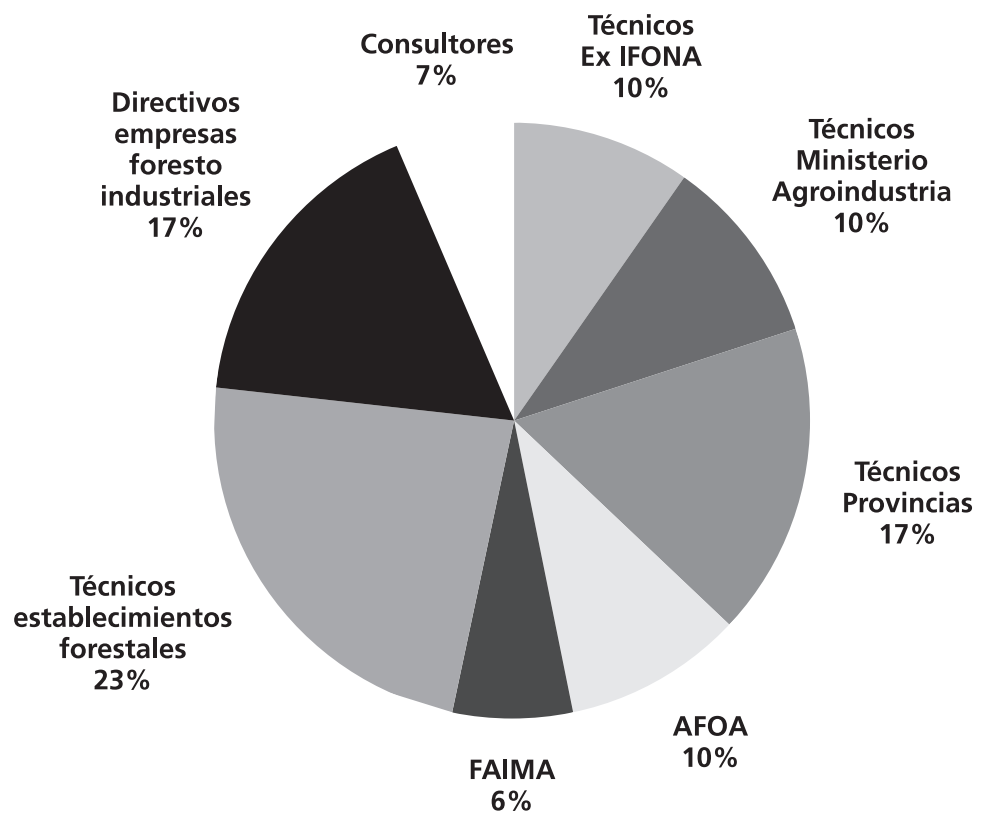

Con el objeto de caracterizar el marco normativo, las políticas y los instrumentos de incentivos forestales utilizados, se efectuó una revisión histórica, tomando como punto de partida la sanción en 1948 de la Ley 13273 de "Defensa de la riqueza forestal". En este punto se pretende esclarecer las condiciones que dieron origen a las políticas y los 
resultados producidos hasta la fecha. En efecto, después de siete décadas desde la sanción de la Ley 13273, cuyo capítulo "Fomento" puede considerarse como el inicio de la política de promoción a las plantaciones forestales comerciales, y transcurridas dos décadas desde la entrada en vigencia del régimen de promoción de las inversiones forestales instituido por la Ley 25080 (diciembre de 1998), se hace necesario generar un nuevo marco conceptual para discutir y/o reformular las políticas de promoción de las plantaciones.

El documento se estructura de la siguiente forma: a continuación de la presente introducción, se analiza el contexto histórico con el fin de puntualizar los principales sucesos a nivel local, regional y mundial que influyeron en el desempeño del sistema forestal argentino. Seguidamente, se describe la evolución del sector foresto industrial de plantaciones en el Cono Sur (Argentina Brasil, Chile y Uruguay) con el objetivo de comparar el crecimiento en esos países y evaluar específicamente lo acontecido en Argentina a la luz de las políticas e instrumentos de promoción empleados a lo largo de la historia. Finalmente, las conclusiones y recomendaciones proponen nuevos principios de intervención por parte del Estado Nacional a reflejarse en el nuevo marco legal a implementarse en los próximos años.

\section{Contexto y modelos de desarrollo que influyeron en las políticas forestales}

Desde principios del siglo veinte, y como consecuencia del avance de la frontera agropecuaria, se comenzó a analizar la explotación de los bosques nativos en los ámbitos académicos y técnicos (algunos gubernamentales), circunstancia que condujo a la generación de antecedentes dispersos que legislaban sobre aspectos parciales de la extracción de madera y produjo los primeros estímulos a la forestación, a través de la Dirección de Tierras de la Nación (Inspección Técnica de Yerbatales y Bosques y posteriormente la Sección Forestal). Así, se emitió una cantidad de disposiciones tendientes a detener el deterioro y la depredación de los bosques que en los entonces territorios nacionales se daban en concesión o eran eliminados para ampliar la citada frontera, procurando, a la vez, estimular la realización de forestaciones.

La posición de Argentina en el mundo desde mediados del siglo XIX hasta la Gran Depresión puede describirse como la aceptación de un lugar bien definido (y destacado) en el sistema de división internacional del trabajo implícitamente surgido bajo el auge del Imperio Británico (Audino y Tohmé, 2001). Dicho sistema asignó a la República Argentina el rol de productor de alimentos y materias primas agropecuarias e importador de productos industriales. Cabe señalar que ese rol comprendía la producción agropecuaria y una incipiente industrialización de recursos naturales que no se podían producir en el continente europeo, como el tanino (extraído del Parque Chaqueño). En consecuencia, tanto la expansión de la producción agropecuaria como de la industria alimentaria se basó en la demanda externa. La crisis de desabastecimiento de combustibles, insumos, bienes industriales y finales provocada por la primera guerra mundial (1914-18) marca el surgimiento de algunos sectores industriales orientados a la sustitución de importaciones cuyo crecimiento se sustentaba en 
el mercado interno y un aumento de la presión extractiva sobre los bosques nativos para proveer leña. El fin de la guerra y la subsecuente normalización del flujo importador generaron un debate entre aquellos sectores partidarios del librecambio que propugnaban retornar al modelo de la preguerra y una corriente de pensamiento proteccionista e industrialista que sostenía que para consolidar en el país el desarrollo de una industria era necesario implementar un sistema arancelario orientado a impulsar la industrialización. Adicionalmente, se postulaba que para favorecer la exportación de productos con un mayor valor agregado era necesario que la acción del Estado se concentrase en la generación de una infraestructura que estimulara la diversificación económica y el desarrollo del interior del país; en darle apoyo crediticio al sector industrial privado y en facilitar la enseñanza profesional de los actores sectoriales (Audino y Thomé, 2001). Este debate se saldó cuando los intereses económicos y políticos de ideología liberal predominantes en sector productivo primario impusieron el regreso al modelo agroexportador.

La Gran Depresión marcó el fin del modelo internacional de la división del trabajo y la adopción generalizada a nivel mundial de políticas comerciales proteccionistas que cerraron los mercados externos a las exportaciones tradicionales argentinas. Esa crisis derivó en el cierre de la economía argentina y creó los incentivos para una mayor industrialización del país, porque ya no era viable impulsar la expansión económica del país basándose solamente en las exportaciones y en la apertura hacia el exterior (Cortés Conde, 2009). En este contexto surge un modelo de desarrollo industrial basado en la sustitución de importaciones (ISI), cuyo concepto central postulaba que no había que comprar en el exterior aquellos bienes de consumo que podían producirse en el país.

La primera fase del modelo ISI modificó la matriz productiva de Argentina, aumentando la participación porcentual de las manufacturas nacionales en el PBI. En el marco del modelo librecambista esa participación era del 16,5\%; pasó al 17,7\% en el período 1920-29, 18,4\% en 1930-34, 20,4\% para el período $1935-39$ y al $21 \%$ en $1940-1944$ (Vaccarezza, 2010). Cabe señalar que el crecimiento del sector industrial llevó a aumentar las importaciones de insumos y bienes de capital dada la concentración de la industria nacional en la producción de bienes finales destinados al mercado interno. Estas importaciones debían adquirirse con las divisas generadas por las exportaciones del sector agropecuario, que era el único competitivo en los mercados internacionales. Esta dicotomía entre un sector industrial concentrado en mercado nacional con una demanda creciente de divisas y un sector agroexportador sujeto a las fluctuaciones de los precios en los mercados internacionales generó en el año 1949 la primera crisis de divisas del país (Cortés Conde, 2009).

Esa crisis evidenció las limitaciones de una industrialización centrada en la industria liviana productora exclusivamente de bienes finales, dando lugar en la década de 1950 a una segunda etapa del proceso sustitutivo orientada estimular el desarrollo de la industria pesada. Esta etapa fue impulsada por el gobierno de Arturo Frondizi (1958-1962), 
que representaba al pensamiento económico del desarrollismo; y fue continuada con diversas políticas hasta 1976. Este pensamiento postulaba que, para superar las crisis de la balanza de pagos era necesario impulsar a los sectores industriales de base considerados claves por su capacidad para desarrollar otras actividades económicas relevantes con la finalidad de disminuir la insuficiencia de la economía nacional para generar divisas. Entre los mismos se pueden citar a los sectores petrolero, químico, siderúrgico, de máquinas herramientas, automotriz y celulósico. Cabe señalar que un rasgo común a las diferentes variantes del desarrollismo implementadas en América Latina fue que se centraron en la sustitución de importaciones ya que consideraban que las exportaciones primarias no eran relevantes para impulsar el desarrollo nacional (Sikkink, 2009).

A partir de las décadas de 1960 y 70, varios países asiáticos reemplazaron exitosamente el modelo ISI por el modelo de Industrialización Orientada a la Exportación (IOE), tal como expresa Cheliz en 2002, especializándose inicialmente en aquellos sectores industriales maduros en los que podían competir con precios bajos para después avanzar en sucesivas etapas a productos industriales de mayor complejidad tecnológica.

Cabe señalar que los modelos ISI y IOE tienen muchos aspectos en común: en una fase inicial se caracterizan por protección al mercado interno mediante cuotas de mercado, aranceles, tipo de cambio alto para posteriormente centrarse en aranceles y subsidios a la exportación en muchos casos complementado por devaluaciones "competitivas" destinadas a mantener un tipo de cambio alto. No obstante, en etapas posteriores comienzan a diferenciarse ya que el modelo ISI se detiene en la fase de protección arancelaria y subsidios a las exportaciones mientras que el modelo IOE comienza a reducir paulatinamente los aranceles y a eliminar los subsidios a las exportaciones hasta llegar a la neutralidad de los incentivos a las industrias exportadoras y sustitutivas y a un tipo de cambio plenamente convertible (Cheliz, 2002).

Asimismo, los países asiáticos que venían aplicando el modelo IOE generaron en la década de 1990 el surgimiento de una clase media hasta entonces inexistente, situación que a su vez provocó un incremento de la demanda mundial de productos celulósico-papeleros, en especial y madereros en general. Dado que -paralelamente- los principales grandes productores y exportadores forestales tradicionales como Suecia, Finlandia, Canadá y Estados Unidos comenzaron a manejar de manera sustentable sus bosques nativos de coníferas (base de su abastecimiento), se produjo, en consecuencia, un impacto en la reducción de la producción de materia prima destinada a satisfacer la demanda incremental asiática. En este marco, el aumento de la producción de materia prima industrializable pasó a depender del establecimiento de plantaciones de coníferas de rápido crecimiento en Australia, Nueva Zelanda, Indonesia y otros países del sudeste asiático, proceso al que se sumaron, por una cierta tradición forestadora, Chile, Brasil y -desde la década de 1980- Uruguay (Bowyer, 2004). 
El otro factor relevante en el desarrollo de las políticas forestales fue el fenómeno de la globalización, entendida como "la creciente gravitación de los procesos económicos, sociales y culturales de carácter mundial sobre aquellos de carácter nacional o regional" (CEPAL, 2012). En este nuevo contexto se produjo una relocalización de las etapas primaria e industrial de bajo valor agregado en las economías recientemente industrializadas del tercer mundo mientras que las etapas de mayor valor agregado se mantienen en los países desarrollados (Gereffi, 2001). La globalización provocó una desintegración vertical en las multinacionales que se reenfocaron hacia actividades de innovación, marketing y a los segmentos de mayor valor agregado de producción y servicios a la vez que se desprendieron de las actividades de servicios genéricos y producción en masa (Gereffi et al., 2005). Esta fragmentación de los procesos de producción permite que las actividades productivas localizadas en diferentes países conformen un entramado internacional que puede ser tanto intra empresa como entre empresas, que se complementa con la integración del comercio internacional (Gereffi, 2001). La necesidad de coordinar las diferentes etapas productivas impulsó el surgimiento de las cadenas globales de commodities y conlleva la introducción del concepto de gobernanza, definida como "la coordinación que algunos actores ejercen directa o indirectamente sobre los sistemas globales de producción, logística y marketing" (Gereffi et al., 2001). La evidencia empírica permite afirmar que la mencionada coordinación es ejercida por las empresas de los países desarrollados. Para el sector forestal internacional, la globalización se manifestó con el traslado de las etapas de plantación y de parte de la producción de pasta celulósica a los países en desarrollo.

\section{Conformación del sector forestoindustrial}

La Ley 13273 de 1948, de Defensa de la Riqueza Forestal tuvo como objetivo principal la regulación de cuestiones vinculadas a los bosques nativos, aunque en el "Capítulo de Fomento" promovía la forestación. Como ya se dijo, esta ley constituye el primer hito normativo que planteó e implementó de manera concreta una serie de instrumentos destinados a la promoción del desarrollo forestoindustrial. A modo de ejemplo la Administración Nacional de Bosques (ANB), posteriormente llamada Instituto Forestal Nacional (IFONA), organismo de aplicación de la ley, creó una red de estaciones y viveros forestales, plantaciones forestales experimentales y un servicio de semillas forestales para impulsar el crecimiento del incipiente sector forestador, en el marco del modelo ISI vigente. Posteriormente con el proyecto de política desarrollista se procuró el reemplazo de las importaciones de pasta celulósica y de madera aserrada, productos que constituían, después de los combustibles y lubricantes, el segundo y tercer rubro de importancia de las importaciones (Castiglioni y Tinto, 1968).

Dado que una limitante para el aumento de la producción de pastas celulósicas era la carencia de una disponibilidad significativa de especies nativas aptas como materia prima (maderas blandas, claras y de longitud de fibra adecuada), de acuerdo a la tecnología mundial existente 
en esos tiempos, la política sectorial se basó en dos líneas de impulsión: una orientada específicamente a la industria materializada mediante el financiamiento del sector público y la protección arancelaria y la otra dirigida a promover la creación de una base de plantaciones forestales capaz de abastecer a la industria de materia prima, conformada por especies exóticas de rápido crecimiento, integrada en su casi totalidad por pinos, eucaliptos y salicáceas.

La política de promoción desde el estado nacional se completó y apoyó técnicamente en el conocimiento acumulado a partir de la introducción de numerosas especies de coníferas de regiones templadas y templado-frías para usos agropecuarios y paisajísticos, básicamente de Europa y EE.UU. y eucaliptos de Australia. La incorporación a los organismos del Estado Nacional de ingenieros forestales provenientes de Europa Central, junto al envío de ingenieros agrónomos argentinos a formarse en las escuelas forestales de Europa, contribuyó a mejorar el sustento técnico del modelo forestal adoptado con el objetivo de fomento a las plantaciones con destino principalmente celulósico. Desde el comienzo de la década de 1960 la intervención del Estado nacional incluyó, además de los incentivos económicos, cierto apoyo científico-técnico, general para todo el país, materializado por programas de mejoramiento genético a cargo del Instituto Nacional de Tecnología Agropecuaria (INTA), universidades públicas nacionales y en menor medida el Consejo Nacional de Investigaciones Científicas y Técnicas (CONICET). En materia industrial, se crearon dos organismos específicos de investigación a cargo del Instituto Nacional de Tecnología Industrial (INTI): el Centro de Investigación para el Estudio de la Celulosa y el Papel (CICELPA) ${ }^{2}$ y el Centro de Investigación Tecnológica de la Madera (CITEMA), hoy llamado "INTI Madera y Muebles". En el campo de la formación de recursos humanos, con el apoyo de la Organización de las Naciones Unidas para la Alimentación y la Agricultura, (FAO) se crearon las dos primeras carreras de ingeniería forestal en universidades públicas nacionales: en 1958 en Santiago del Estero y en 1960, en La Plata (Denegri et al., 2017). Un hito no menor en el plano del diseño y ejecución de las políticas destinadas al sector forestal fue la disolución del IFONA en el año 1991 (Decreto N 2284/91), lo cual implicó una escisión -no superada hasta la fechaen cuanto al plano institucional y las políticas destinadas a los bosques nativos y plantaciones forestales. Con el objeto de proteger al mercado interno se establecieron altos aranceles a la importación de celulosa y papel; a modo de ejemplo, para 1965, el arancel para toda pasta celulósica era del $30 \%$ y de 65 hasta $220 \%$ para papeles, salvo los de diarios y destinados a la industria editorial que era del 20\% (Chidiak y Bercovich, 1995).

\section{Instrumentos de promoción a las forestaciones}

La Ley 13273 promovía la forestación mediante el otorgamiento de créditos a tasas subsidiadas, la desgravación del impuesto a las ganancias a personas fisicas y jurídicas que realizaran forestaciones y la exención del impuesto inmobiliario a las superficies forestadas. No obstante, el comienzo de las plantaciones comerciales en gran escala para producir madera para aserrados y celulosa recién se produjo en la década de 1960. Los créditos eran 
de carácter especial para la forestación, reforestación, industrialización y comercialización de la producción forestal, adecuando los plazos y tipos de interés, a cargo del Banco de la Nación Argentina y el Banco de Crédito Industrial Argentino (BCIA), antecesor del Banco Nacional de Desarrollo (BANADE) cuyo objetivo central era financiar inversiones y capital de trabajo a largo plazo para las industrias (Rougier, 2007). En cuanto al segundo instrumento (desgravación impositiva), el mismo se aplicaba a las utilidades que se invirtiesen en nuevas plantaciones y las mejoras silvícolas en general. Además, se estableció la exención del 100\% del impuesto inmobiliario a las superficies forestadas en los territorios nacionales y de no menos del 50\% -o la cantidad establecida por las leyes de adhesión- de las jurisdicciones provinciales. Cabe señalar que, mayoritariamente, las provincias adoptaron el criterio del 100\% de exención de tributo. Este beneficio se hacía extensible a los bosques definidos como protectores en la norma precitada.

Con la sanción en 1973 de la Ley 20628 de Impuesto a las Ganancias se generó un nuevo impulso a las plantaciones forestales. La norma establecía en su artículo 111 que "para la determinación de la materia imponible, cualquiera fuese el origen de la ganancia, serán deducibles las inversiones en nuevas plantaciones forestales o en la ampliación de las existentes. Las inversiones antedichas podrán realizarse en forma directa o a través de integración de acciones, bonos, certificados o cualquier otro tipo de valores destinados a financiar las inversiones". Mediante el Decreto 465/74 se reglamentaron los beneficios impositivos para los inversores en nuevas plantaciones forestales, permitiéndose desgravar del cálculo del impuesto aplicable el valor del crecimiento de la masa forestal. Como resultado de esta política se produjo un aumento de la superficie de bosques de cultivo, cuya magnitud se estimaba para el año 1978 en, aproximadamente, 650.000 hectáreas distribuidas en todo el país como se aprecia en la figura 3.

Figura 3. Evolución de la superficie forestada en Argentina (1960-2015)

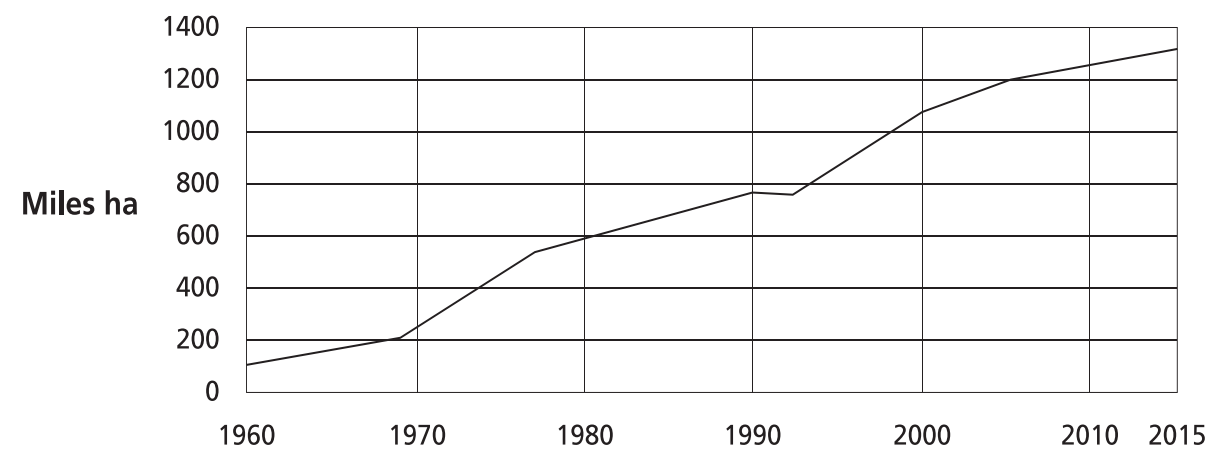

Fuente: Elaboración propia con base en datos de Denegri y Aguerre (1996) y Ministerio de Agroindustria (2018) 
En 1977 se produjo un cambio conceptual en el modelo de promoción, con la sanción del Decreto Ley 21695 de "Estímulos fiscales para la forestación” que reemplazó la desgravación impositiva por un sistema de crédito fiscal transferible, para la forestación. El crédito era "aplicable al pago de cualquier impuesto cuya aplicación, percepción y fiscalización se encuentre a cargo de la Dirección General Impositiva" (Ley 21695, Mensaje). A dichos efectos, la nueva norma derogó al decreto 465/74 que reglamentaba la desgravación del impuesto a las ganancias y al Fondo Forestal, estableciendo un subsidio a los gastos directos de plantación, consistente en un monto fijo por hectárea y por especie calculado anualmente para cada región por el IFONA, que era el organismo de aplicación. El cupo anual de crédito fiscal destinado al cumplimiento de la ley, se establecía en el presupuesto en base a las estimaciones del IFONA.

La norma establecía que el IFONA debía confeccionar un Plan Nacional de Forestación de 5 años, que, entre otros objetivos, serviría para determinar el cupo global del crédito fiscal y su distribución por zona y por especie, fomentar la forestación selectivamente por región, integrando a los bosques de cultivo con la foresto-industria. Otro cambio sustancial de paradigma consistió en que explícitamente priorizaba la figura de los pequeños y medianos productores familiares, declarando en su mensaje que dichos actores “...son los únicos que, con su esfuerzo sumado, podrían generar en el corto plazo un gran incremento de la superficie forestada...".

El crédito fiscal constituía en los hechos un subsidio del 70\% de un costo modal de forestación, pagado en cuotas según avanzaban los trabajos de plantación, con un adelanto para el inicio de las labores. El bono de crédito se podía aplicar al 100\% de su valor para el pago de los impuestos nacionales o se podía canjear por dinero en efectivo al $95 \%$ de su valor nominal en el Banco de la Nación Argentina. La inestabilidad económica y las restricciones presupuestarias del Estado nacional en la década de 1980 fueron reduciendo su efectividad hasta su derogación en 1989 se derogó. Este régimen produjo un escaso aporte al incremento de las áreas forestadas ya que a su finalización se estimaba una superficie de 750.000 hectáreas (figura 3); menos de un 20\% de aumento en 12 años.

En 1992 se estableció un subsidio directo a las plantaciones a través del Régimen de Promoción de las Plantaciones Forestales, mediante la Resolución 778 de la Secretaría de Agricultura, Ganadería y Pesca (SAGyP) y complementarias, vigente hasta el año 1999. Estableció un "beneficio económico no reintegrable, por especie y por zona" a plantación lograda certificada por la autoridad. Este apoyo económico comprendía tanto a las actividades de plantación como a las operaciones de poda y al primer raleo con el objeto de generar materia prima apta para las industrias de primera y segunda transformación mecánica de la madera. Por primera vez en la historia de las políticas de promoción sectorial se estableció un nivel presupuestario básico de 15 millones de pesos convertibles/dólares para la promoción forestal. Asimismo, estableció un sistema de licitación para las medianas y grandes empresas 
forestales mediante el cual se concursaba por los remanentes de las partidas presupuestarias a quienes presentaban una propuesta técnica adecuada y solicitasen el menor subsidio por hectárea forestada. A diferencia del régimen establecido por la Ley 21695, el beneficio se pagaba en una vez a los 18 meses cuando la plantación estaba lograda.

Durante la vigencia del régimen, a través de las sucesivas resoluciones de la entonces Secretaría de Agricultura, Ganadería, Pesca y Alimentación (SAGPyA), se fueron aumentando los requisitos técnicos en cuanto a densidades de plantación, la obligatoriedad de utilizar material de viveros autorizados por el Servicio Nacional de Sanidad y Calidad Agroalimentaria (SENASA), la realización de caminos cortafuegos y la adopción de medidas de prevención de incendios forestales, entre otras medidas.

Esta etapa alcanzó su máxima intensidad en 1998, con la promulgación de la Ley 25080 de inversiones para bosques cultivados que instituyó por 10 años un régimen de promoción a las inversiones forestales; al apoyo económico no reintegrable del sistema anterior, sumó beneficios fiscales para proyectos foresto industriales integrados. Al completarse su plazo de vigencia, el régimen se prorrogó por otros 10 años por la Ley 26432, es decir con vencimiento en 2018.

Entre las principales características del régimen se señalan: promocionar los bosques de cultivo con finalidades productivas, beneficia a personas físicas, jurídicas y fideicomisos; los proyectos aprobados deben situarse en tierras sin bosques nativos (salvo plan de manejo sustentable en bosque degradado para enriquecerlo), y "realizarse con especies maderables exóticas o nativas adaptadas ecológicamente al sitio, con fines principalmente comerciales o industriales, en tierras que, por sus condiciones naturales, ubicación y aptitud sean susceptibles de forestación o reforestación según lo indicado en el ordenamiento territorial de Bosques Nativos adoptados por ley provincial según lo establecido en la Ley 26331; el beneficio económico no reintegrable cubre hasta el 80\% de los costos en las plantaciones de hasta 300 hectáreas, y el 20\% cuando la extensión implantada se ubique entre las 301 y las 500 hectáreas. Estos valores aumentan para la región patagónica a 500 y 700 hectáreas.

Al igual que la Ley 13273, requiere de la adhesión de las provincias, pero por primera vez se incluye la adhesión de los municipios. Específicamente, la norma se compone de dos tipos de instrumentos de promoción:

\section{A.- Apoyo económico no reintegrable (subsidio)}

La ley 25080 establece categorías de beneficiarios, a los que se exige el cumplimiento de diferentes requisitos, a saber: 
1) Pequeño Productor, hasta 10 ha de plantación y 50 ha de raleos. La presentación del proyecto no requiere de un profesional responsable; 2) Productor Mediano Grande, de 10 a 300 hectáreas; la presentación del proyecto requiere de profesional responsable del mismo; 3) Productores Grandes/Muy Grandes, más de 500 ha.; el proyecto requiere de un profesional responsable y una evaluación de impacto ambiental; 4) Pequeños Productores Agrupados: el proyecto debe tener un técnico y una entidad responsable.

El régimen establece que el beneficio se paga a plantación lograda una vez aprobado el proyecto previa verificación por la autoridad competente. La categoría de agrupados constituye la única excepción a la condición de pago a plantación lograda ya que contempla recibir un adelanto de hasta el 30\% del beneficio.

\section{B.- Beneficios Fiscales (impositivos)}

El régimen prevé diversos incentivos fiscales para las inversiones en proyectos forestoindustriales integrados, pudiéndose resaltar la estabilidad fiscal que implica el mantenimiento de los impuestos nacionales, provinciales, tasas municipales y sus alícuotas vigentes a la aprobación del proyecto (el Impuesto al Valor agregado -IVA- queda excluido del régimen), reintegro para el IVA de los bienes y servicios del componente forestal de los proyectos aprobados, exención de impuestos patrimoniales: ganancia mínima presunta, impuesto a los bienes personales, impuestos a los activos vigentes o a crearse durante la vigencia del proyecto aprobado, exención de impuestos que graven la aprobación de estatutos, contratos, sus ampliaciones, modificaciones, etc., destinados a la organización del emprendimiento (básicamente el Impuesto a los sellos), un régimen optativo de amortización acelerada del impuesto a las ganancias y el avalúo de Reservas: la capitalización debida al crecimiento de la plantación carece de incidencia tributaria alguna.

Como se observa en la figura 3, luego de casi setenta años de apoyo con diferentes instrumentos a la conformación de una masa forestal destinada a la producción industrial, Argentina superó el millón de hectáreas forestadas (1.300.000 ha el año 2018). En la actualidad esta superficie provee una oferta de madera con destino industrial que supera en aproximadamente 10 millones de $\mathrm{m}^{3}$ a la demanda existente para satisfacer el consumo interno y el nivel presente de exportaciones (Agrovoz, 2017). Los autores verificaron esta afirmación dado que el promedio de extracciones en el quinquenio 2010-2014 fue de casi 13 millones de $\mathrm{m}^{3} \mathrm{y}$ la oferta potencial anual, para ese mismo período, por corta de la superficie forestada se estimó entre 20 y 25 millones de $\mathrm{m}^{3}$. Esa brecha depende del crecimiento promedio de las plantaciones utilizado para el cálculo, en este caso se adoptaron valores conservadores: 15 y $20 \mathrm{~m}^{3}$ por hectárea y año y considerando que en los últimos 10 años la superficie cortada ha sido en promedio igual a la plantada. ${ }^{3}$ Por otra parte, en algunas áreas donde las plantaciones carecen de destino industrial se han desarrollado forestaciones que facilitaron la aparición de actividades vinculadas a la creación de paisajes 
turísticos, al desarrollo inmobiliario y a la generación de servicios ambientales que contribuyeron al desarrollo territorial (Denegri et al, 2015; Denegri et al, 2018).

\section{Industrialización}

La industrialización regional de la madera proveniente de forestaciones se consolida en Argentina durante la década de 1970, cuando las plantaciones comenzaron a alcanzar su madurez y de manera progresiva fueron reemplazando a los bosques nativos como fuente de materia prima industrial. La industria de la celulosa y el papel experimentó un período de expansión en las décadas de 1960 y 1970 para satisfacer la creciente demanda interna, con financiamiento desde el estado nacional a través del BANADE. Cumplido el proceso de sustitución de importaciones celulósicas, en la década de 1980 se estancó la producción. El último gran proyecto de producción de pasta celulósica se puso en marcha en 1982 (Alto Paraná SA, Misiones).

La industria celulósica se ubica en seis provincias, concentrando en la provincia de Misiones el 43\% de la producción, mientras que el segundo grupo de localizaciones (Santa Fe, Jujuy y Buenos Aires) supera ligeramente a la producción de Misiones (representa el 47\%).

Figura 4. Argentina: producción de celulosa por provincia, año 2015 (toneladas)

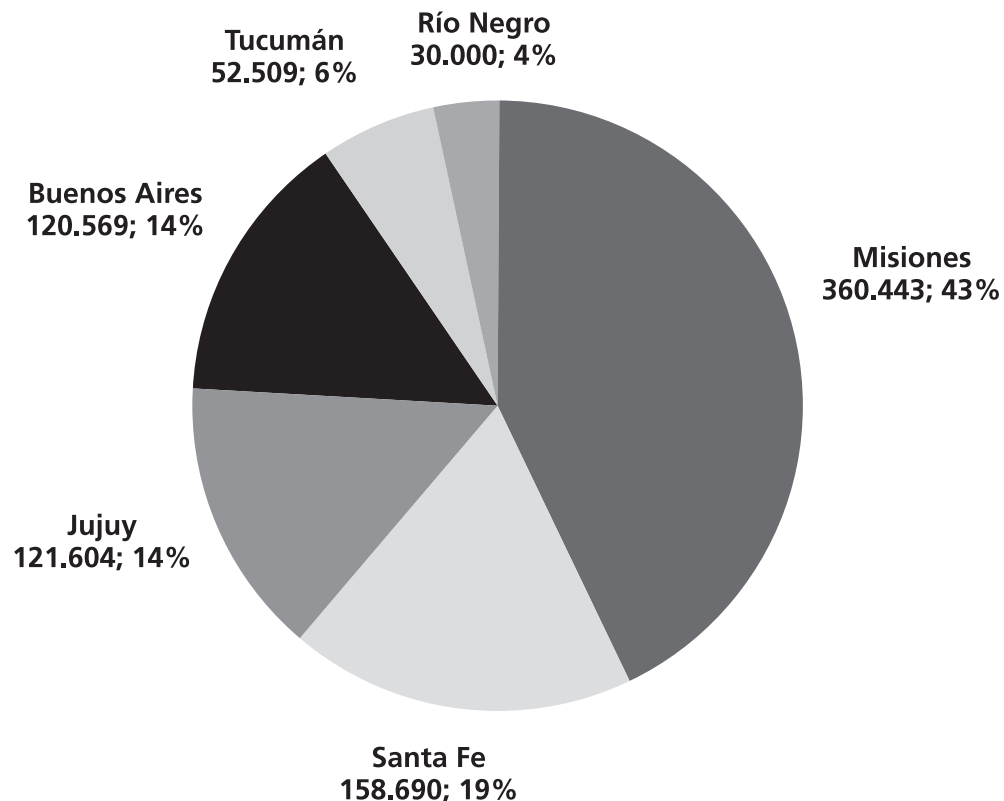

Fuente: Elaboración propia con base en Ministerio de Agroindustria (2015) 
En el año 2015 la balanza comercial para la celulosa fue levemente negativa (13.987.000 USD). El déficit registrado para el mismo período en el rubro papel fue de 746.400.000 USD (Ministerio de Agroindustria, 2015). A fin de evaluar los resultados observados, corresponde recordar que la promoción de la producción de celulosa fue planificada con el solo objetivo de integrarse a la cadena de producción nacional de papel y con el objeto de reducir sustancialmente las importaciones de este último, en el marco del modelo ISI. En ese sentido, Bercovich y Katz (1997), califican como un fracaso a la política de desarrollo celulósico papelera implementada por Argentina: "Nos encontramos ante una experiencia de fracaso en la construcción de un sector industrial...Veremos que el desarrollo del sector se vio atenazado entre una acción estatal mal orientada y peor aplicada y la ineficiencia de los actores privados, lo cual contribuyó a reunir en el sector los aspectos más negativos de lo que se ha dado en llamar la industrialización sustitutiva de las importaciones". Esta comparación se verá en el siguiente apartado.

La política forestal aplicada a partir de los años noventa comenzó a mostrar resultados heterogéneos en las distintas regiones. Las cadenas forestales de la Mesopotamia fueron impulsadas por el ingreso de inversiones externas directas, destinadas a la compra de activos de empresas forestales, y en el subsector industrial se dirigieron a la compra y puesta en valor de activos existentes, esencialmente en el sector celulósico (Aguerre y Denegri, 2004). Por ejemplo, dos grupos celulósicos y dos de tableros industrializados se instalaron allí: Arauco, en Misiones, mediante la adquisición de los activos de Alto Paraná SA, CMPC, en Corrientes, y Sadepan y Masisa, en Entre Ríos (Denegri y Aguerre, 2010).

El surgimiento y evolución de las industrias de la primera y segunda transformación mecánica de la madera y del mueble, a diferencia del celulósico, siempre fue una iniciativa del sector privado en función de la demanda del mercado interno y en el marco de una progresiva adaptación o reconversión en el uso de materia prima proveniente de bosques nativos a madera de forestación, con escaso apoyo estatal inicial. Cabe enfatizar que este proceso se desarrolló en forma paralela al de la promoción de las forestaciones para la industria celulósica. En la actualidad, las industrias de la madera y el mueble, conformada básicamente por pequeñas y medianas empresas (PyMES), están presentes, en desigual medida, en la totalidad del territorio nacional, complementándose con la industria de tableros industrializados de fibra y partículas, concentrada ésta básicamente en la Región Mesopotámica y el Delta Entrerriano Bonaerense (Denegri y Aguerre, 2010).

En la actualidad, los territorios que concentran la mayoría de las plantaciones forestales, presentan gran diversidad en cuanto a los logros obtenidos, la sustentabilidad del sistema o la incorporación de valor agregado. Así, la provincia de Misiones concentra cadenas foresto industriales celulósico-papelera, de tableros industrializados y de aserrado y remanufactura de pinos vinculadas principalmente a la construcción. ${ }^{4}$ En Entre Ríos se localizan cadenas de tableros industrializados, aserrados, remanufacturas, pallets, tarimas y cajones de 
madera de eucalipto. En la parte bonaerense del Delta Entrerriano se conformaron cadenas foresto-industriales, tales como la celulósica papelera, basada en salicáceas, de tableros industrializados, que utiliza eucaliptos y madera reciclable y de aserrados, remanufacturas, envases y tableros compensados, que se abastece de rollizos de salicáceas procedentes del Delta y de eucaliptos de la región pampeana. En las provincias de Corrientes, Córdoba y Neuquén, entre otras, se desarrollaron cadenas ligadas centralmente al aserrado y remanufactura, envases, pallets, tarimas y muebles (Denegri et al., 2016). Muchas de estas cadenas regionales, que inicialmente se abastecieron de maderas provenientes del bosque nativo, en la actualidad aún se encuentran en una fase de transición al empleo de materia prima proveniente de plantaciones, en muchos casos de origen extraprovincial.

Figura 5. Argentina: producción y exportación de madera aserrada y remanufacturas procedentes de plantaciones forestales (1970-2015)

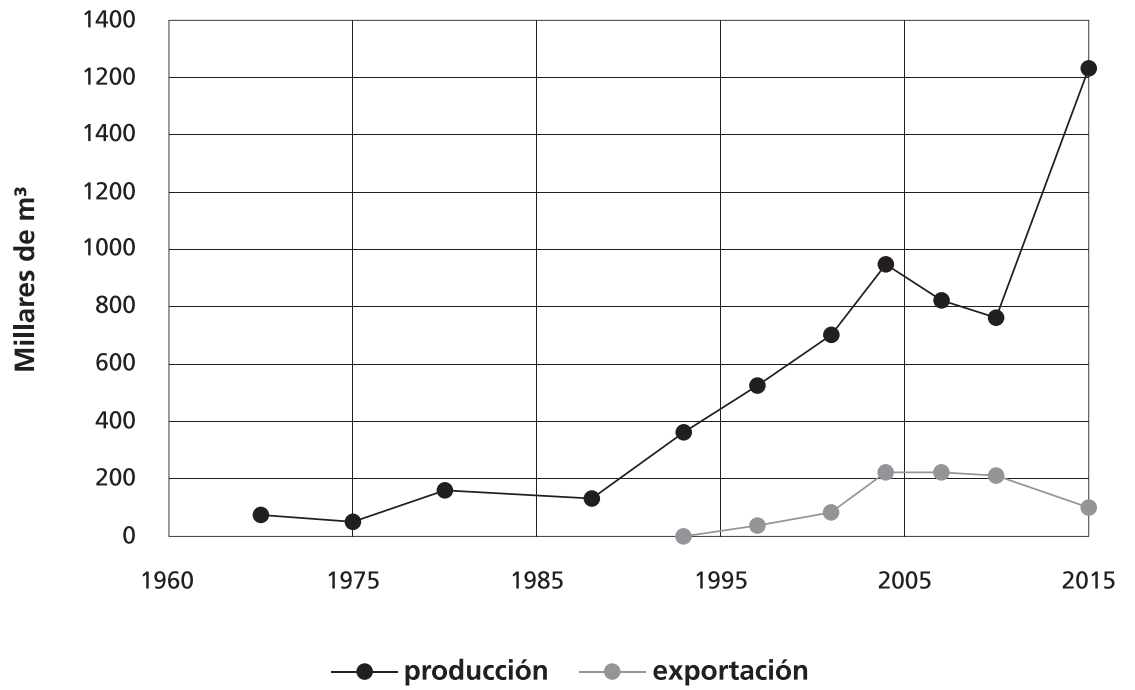

Fuente: Elaboración propia con base en FAOSTAT (2017).

En la figura 5 se aprecia que la producción de aserrados y remanufacturas de madera procedente de plantaciones forestales, pese a la ausencia de medidas de promoción estatal, ha evidenciado un mayor dinamismo que la celulosa, tanto en la producción como en la exportación. Cabe señalar que ese dinamismo de la cadena no fue sólo consecuencia del mercado interno, sino que fue impulsado por las transformaciones ocurridas en el comercio internacional de aserrados de coníferas ocurrido en la década de los 90, a saber: Estados Unidos pasó de ser un exportador neto a un importador de aserrados debido a las restricciones ambientales implementadas por el Servicio Forestal Federal al aprovechamiento de los bosques federales (Denegri et al., 2017). Esta circunstancia permitió que, como consecuencia de la existencia de forestaciones de pino en las provincias de Misiones y Corrientes, la llegada 
de inversiones extranjeras y la realizada por empresas medianas locales, la región se insertó en el mercado internacional de madera de coníferas. Cabe aclarar que más del 90\% de las exportaciones de aserrados desde Argentina fueron de madera de coníferas.

Paralelamente, a partir del año 2000, y por primera vez desde el período previo a la Gran Depresión, se comenzó a gestar una burbuja inmobiliaria. ${ }^{5}$ En este marco, en el período 2000 a 2005 el número de unidades habitacionales construidas anualmente aumentó de 1,5 millones a 2 millones aproximadamente (Byun, 2010). Esta expansión provocó un desbalance entre la oferta y la demanda norteamericana de aserrados y remanufacturas para la construcción que se cubrió con importaciones principalmente de Canadá y en menor medida de Suecia, Finlandia, Chile, Brasil y en un volumen mucho menor aún de Argentina. A nivel interno puede señalarse que, a partir de la crisis del 2001, hubo un tipo de cambio elevado hasta el año 2007 (BCRA, 2016), circunstancia que operó como un elemento potenciador de las exportaciones. Durante el año 2007 se produjo el denominado "estallido de la burbuja hipotecaria" desencadenando una crisis en el mercado inmobiliario de tal magnitud que provocó que desde fines de dicho año hasta el 2008 inclusive se perdiese una década de crecimiento de la inversión en propiedades (Byun, 2010).

Como consecuencia de lo expresado en el párrafo anterior, las exportaciones argentinas de aserrados y remanufacturas de pino experimentaron una reducción que las empresas exportadoras compensaron redireccionando su producción al mercado interno provocando una sobreoferta que afectó principalmente a las PyMES foresto industriales (Misiones Online, 2013). Este ciclo finalizó en 2011, coincidiendo con la recuperación en Estados Unidos de la construcción de viviendas unifamiliares. No obstante, la industria local no pudo retomar el nivel de exportaciones previo a la crisis del 2008 debido al aumento de los costos internos en dólares estadounidenses producto de la apreciación del tipo de cambio real multilateral. Específicamente, se pasó de un promedio para el período 2002 2007 de 157,6 a 114,1 millones de dólares en el período 2008 a 2016 (BCRA, 2016). Las restricciones para exportar, agravadas por el descenso del consumo interno, provocaron una reducción del nivel de la actividad (Misiones Online, 2013; Misiones Online, 2014).

Si bien la industria del aserrado y sus derivados tiene una baja incidencia en el PBI de Argentina (1,5\% según FAO), la actividad forestal presenta una alta incidencia en algunas economías regionales. Por ejemplo, en Misiones representa 40\% del PB geográficoSegún la Federación Argentina de la Industria Maderera y Afines (FAIMA), el empleo generado por el sector maderero nacional es de 500.000 puestos directos de trabajo; Carabelli (2010) consigna un total de 235.000 para todo el sector. Asimismo, la tabla 1 muestra el número de plantas industriales y los puestos de trabajo en las principales regiones forestales para 2014. Lo expresado permite inferir que el análisis de la importancia del subsector maderero debe efectuarse a escala regional y no nacional, dadas las características de los actores y empresas que lo conforman. 
Tabla 1: Estimación del número de plantas y puestos de trabajo generados por la industria maderera en las principales regiones forestales de Argentina (2014). Fuente: elaboración propia en base a consulta a informantes calificados, Mac Donagh et al., (2016) y Ministerio de Agroindustria de la Nación (MINAGRI).

\begin{tabular}{|l|l|l|l|l|l|l|}
\hline \multirow{2}{*}{$\begin{array}{l}\text { Región } \\
\text { Provincia }\end{array}$} & Aserraderos & & \multicolumn{3}{|l|}{ Plantas remanufactura } & \multicolumn{2}{l|}{ Aserraderos e industrias derivadas } \\
\cline { 2 - 7 } & $\begin{array}{l}\text { Número de } \\
\text { establecimientos }\end{array}$ & $\begin{array}{l}\text { Personal } \\
\text { ocupado }\end{array}$ & $\begin{array}{l}\text { Número de } \\
\text { establecimientos }\end{array}$ & $\begin{array}{l}\text { Personal } \\
\text { ocupado }\end{array}$ & $\begin{array}{l}\text { Número de } \\
\text { establecimientos }\end{array}$ & $\begin{array}{l}\text { Personal } \\
\text { ocupado }\end{array}$ \\
\hline Corrientes & 228 & 2.100 & 309 & 18.000 & & \\
\hline Delta Bonaerense & & & & & 40 & 270 \\
\hline Entre Ríos & & & & & 220 & 1.500 \\
\hline Misiones & 750 & 8.300 & 1.000 & 25.600 & & 360 \\
\hline Neuquén & & & & & 60 & \\
\hline
\end{tabular}

\section{Comparación con los países del Cono Sur}

En el marco de los procesos de globalización Brasil, Chile y Uruguay recibieron inversiones para plantaciones forestales, fundamentalmente para industrias productoras de celulosa. En ese contexto, Chile se consolidó como un exportador de productos forestales especializado en madera de pino. En 2015 contaba con 2.384.000 de hectáreas de plantaciones forestales que proveen la materia prima para la producción de pastas celulósicas, tableros de fibras y partículas, aserrados y remanufacturas de madera. Brasil, que siempre fue un importante exportador mundial de madera de sus bosques y selvas nativas, generó 7.736.000 de hectáreas de plantaciones, para el año 2015, cuyo principal destino fue la industria siderúrgica y celulósica, y, además, consolidó una industria del papel de escala internacional. El caso más reciente es Uruguay, cuyo proceso forestador en gran escala se desarrolló a partir de la década del 1990, ya tenía en 2015 una superficie de 1.062 .000 hectáreas de forestaciones, recibiendo inversiones en el siglo XXI en el sector celulósico que lo convirtieron en un importante exportador de ese producto (FAOSTAT, 2017).

Figura 6. Evolución de la superficie forestada por país en el Cono Sur (1960-2015)

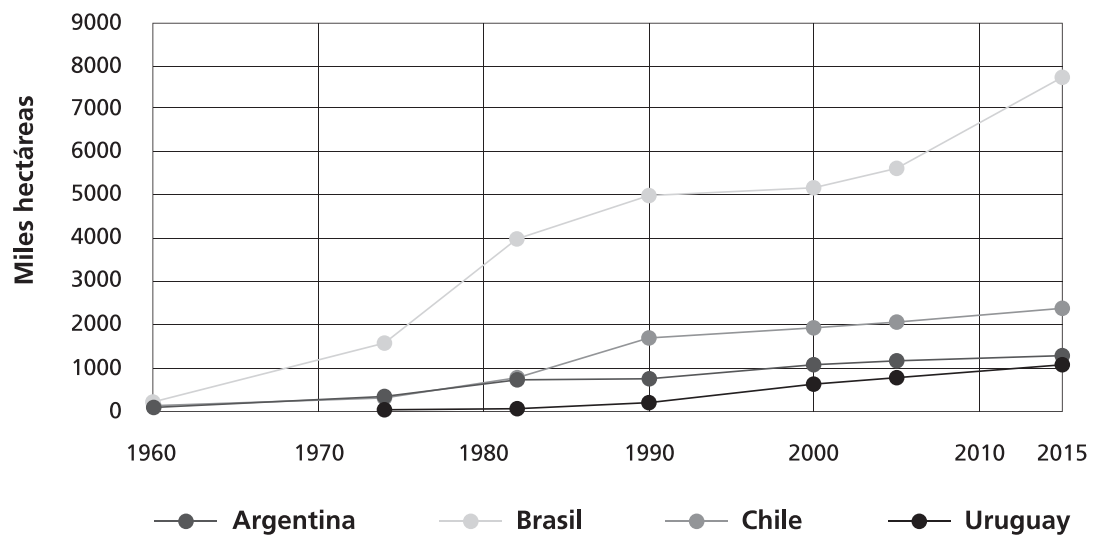

Fuente: Elaboración propia con base en FAOSTAT (2017) 
En este punto es pertinente analizar con mayor detalle lo acontecido en el Cono Sur desde década de 1970, tanto en superficie plantada como en producción industrial. Del análisis de la figura 6 se infiere que Argentina es el país que menos aumentó su superficie durante todo el período (1.089\%), mientras que Brasil es el que más la incrementó (2.875\%). Por su parte, Uruguay superó el 2000\% (2.024\%), alcanzado el millón de hectáreas en 2015 y Chile es el tercero en la serie en cuanto a su expansión (1.882\%). Se observa también, que Argentina y Chile arrancan con condiciones semejantes en 1960 con aproximadamente 100.000 ha, pero el segundo país en 1982 ya supera a Argentina en superficie forestada y en 2015 la duplica. Uruguay llegó al millón de hectáreas en 2015 cuando en 1990 tenía el 26\% de la superficie forestada por Argentina. Finalmente, Brasil -claro líder en superficie forestada- pasó de duplicar en 1960 la superficie plantada en Argentina a superarla en casi 6 veces en 2015 (más de 7 millones de hectáreas). Adicionalmente, para el período 2005-2015, Argentina presenta la tasa más baja de crecimiento de su superficie acumulada (11,51\%), frente al resto de los países del Cono Sur (Brasil: 37,65\%; Uruguay: 35,81\% y Chile: 15,56\%). Al comparar la superficie forestada acumulada de Argentina con las de los otros países del Cono Sur, se observa que desde 1960 a 2015 siempre fue menor a la de Brasil, casi igual con Chile (hasta 1982), mientras que superó a Uruguay para el mismo lapso, si bien con una tendencia claramente declinante.

A fin de analizar comparativamente el desempeño de la transformación mecánica, se recurrió a la madera aserrada de coníferas, dado que se trata del principal producto de exportación de Argentina. En esta gama de productos, tal como se aprecia en la figura 7 , se destaca el crecimiento constante de Chile, que en 1970 producía 630.000 m3 y pasó a ocho millones en 2015. En el caso de Brasil se debe hacer una aclaración: mientras que en 1970 la principal exportación fue de Araucaria angustifolia ("pino Brasil”), madera nativa que en la actualidad casi no produce como consecuencia del proceso de deforestación que sufrieron sus bosques, en 2015 produjo $8.600 .000 \mathrm{~m} 3$ de madera cultivada de pinos exóticos (Pinus spp). Con respecto a Uruguay y Argentina, la producción en ese período, se multiplicó por 10 y 22 veces respectivamente. 
Figura 7. Producción de aserrados de Coníferas en el Cono Sur (1970-2015)

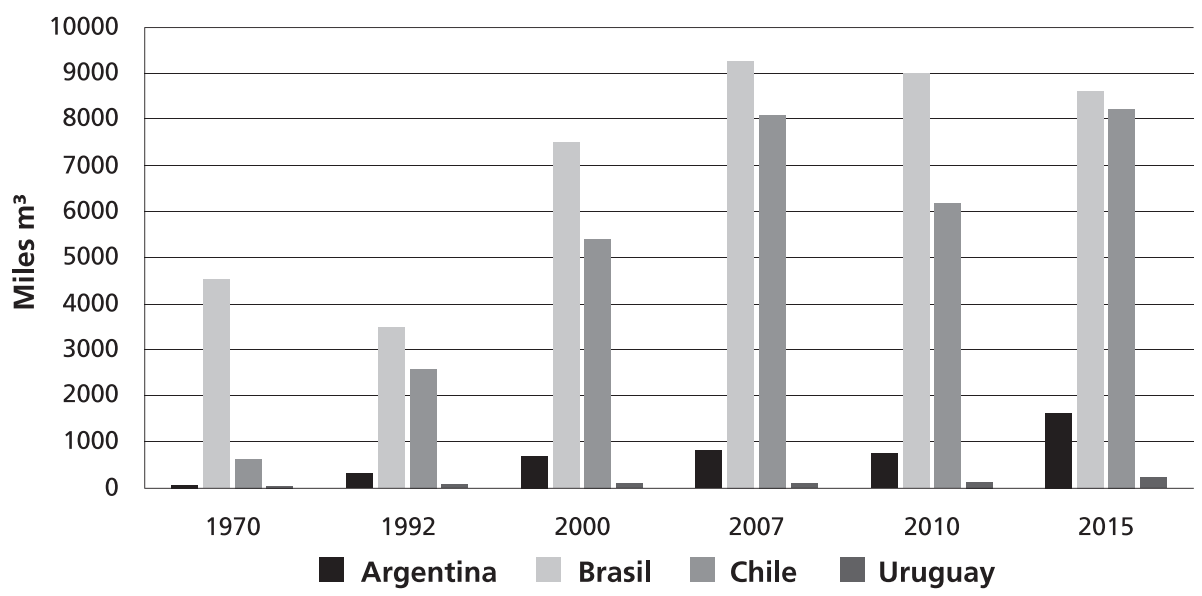

Fuente: Elaboración propia con base en FAOSTAT (2017)

Para todo el período analizado se observa que, así como Brasil es el líder en la producción, Chile lo es en las exportaciones desde 1992, consecuencia de planificar su modelo forestal dirigiéndolo a los mercados externos. Asimismo, Uruguay aparece desde 2007 como un incipiente exportador, a la par de que Argentina exhibe un desempeño declinante. A diferencia de Argentina, Chile y en menor medida, Brasil, las exportaciones acompañaron la evolución del mercado de la vivienda de Estados Unidos, tanto en la fase de expansión, como en la declinación y en la posterior recuperación (figura 8).

Figura 8. Exportación de aserrados de coníferas en el Cono Sur (1970-2015)

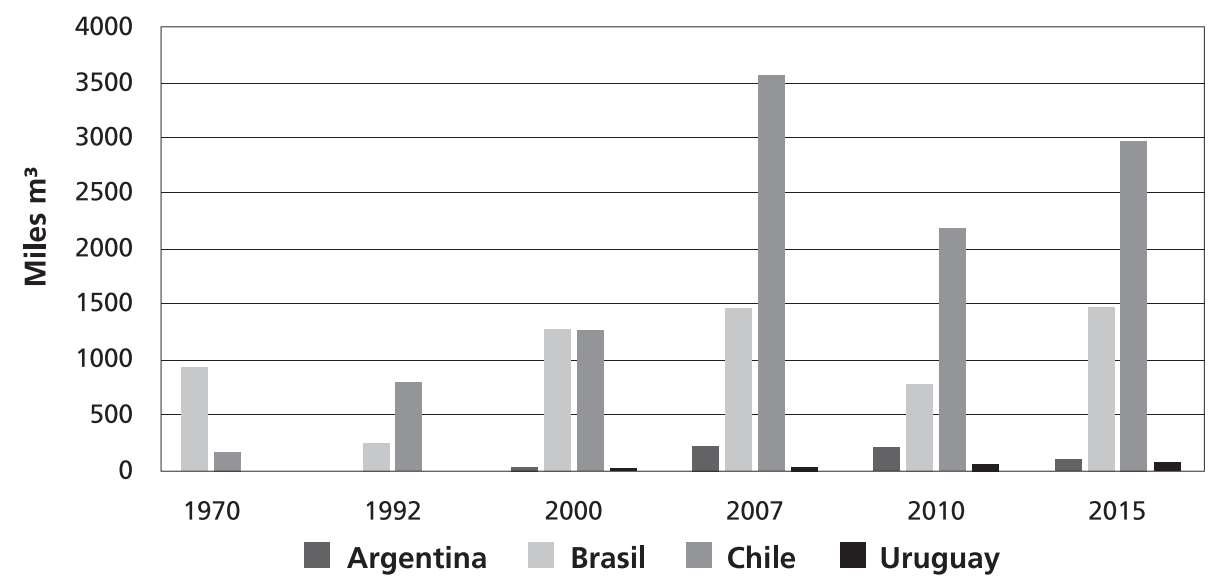

Fuente: Elaboración propia con base en FAOSTAT (2017) 
En cuanto a la producción de pastas celulósicas (figuras 9 y 10), Brasil es principal productor regional en todo el período analizado, superando entre 1.7 a 2.1 veces la producción del resto de los países. Chile es el segundo productor, mientras que en el año 2013 Uruguay se constituyó en el tercer productor regional. Cabe destacar el estancamiento ya analizado de la producción argentina. Similares observaciones se pueden efectuar con respecto a la exportación (figura 10). Brasil produjo 12.500 .000 toneladas en el año 2015 y exportó 9.500.000, Chile totalizó 4.323 .800 toneladas y exportó 4.000 .000 t; mientras que en 1970 produjo 200.000 y exportó 100.000. Por último, Uruguay en 2013 produjo 1.240.000 toneladas, exportando casi la totalidad de la producción.

Figura 9. Producción de celulosa en el Cono Sur (1970-2013)

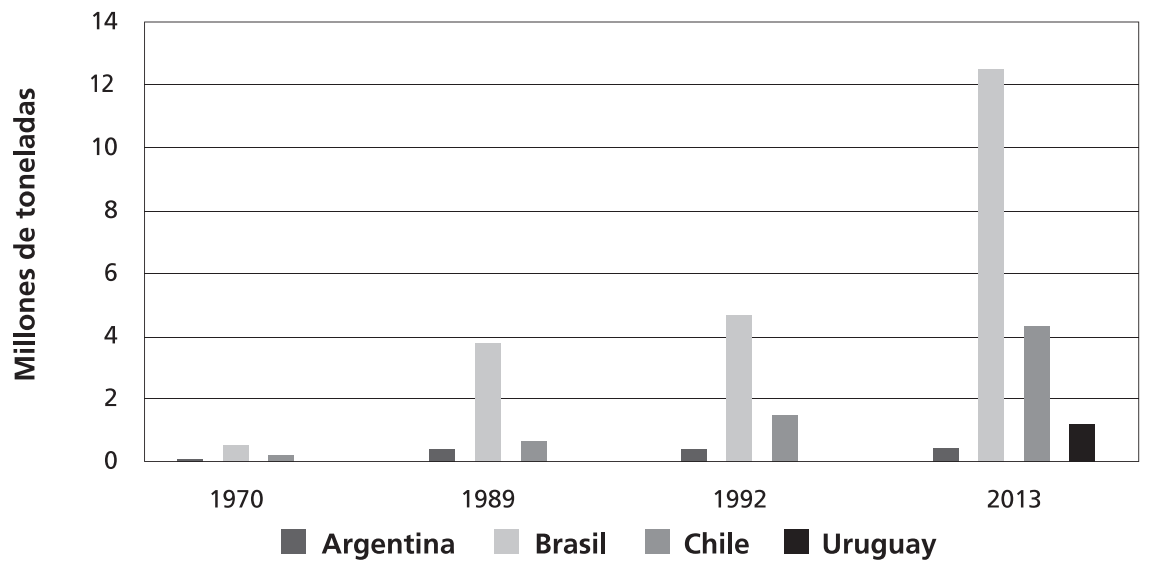

Fuente: Elaboración propia con base en FAOSTAT (2017)

Figura 10. Exportación de celulosa en el Cono Sur (1970-2013)

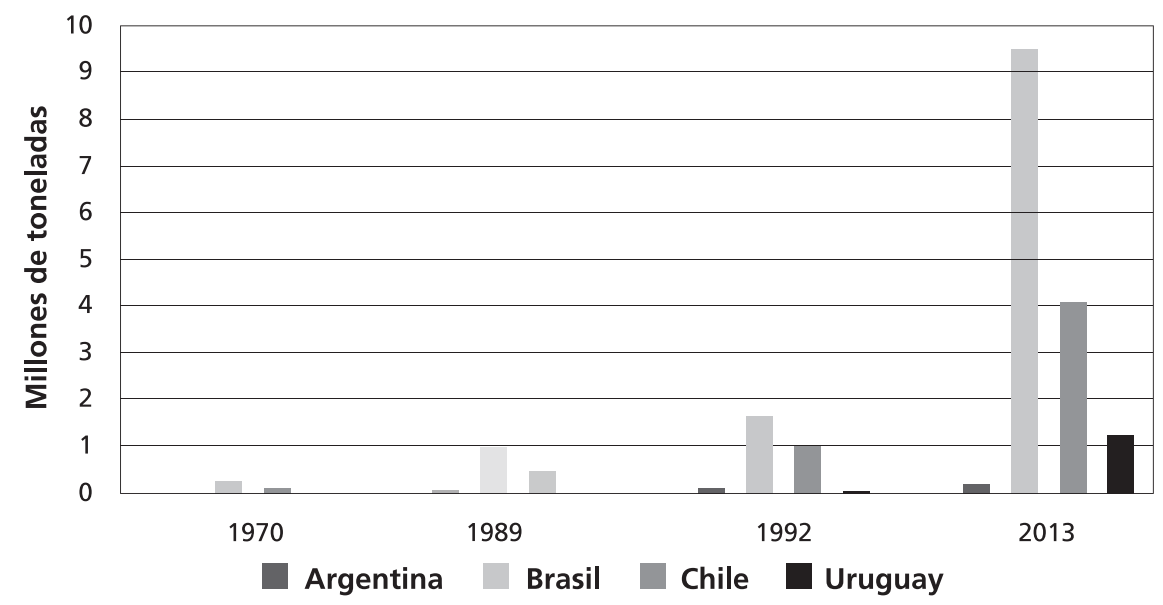

Fuente: Elaboración propia con base en FAOSTAT (2017) 
Por último, cabe aclarar que la globalización transformó progresivamente a la pasta celulósica en una commodity, basando la competencia en la reducción de costos como resultado de la economía de escala productiva de las plantas industriales. En este, sentido Bercovich y Chidiak (1995) señalan que entre 1970 y 1990 la capacidad media de las industrias de Suecia, Finlandia y Estados Unidos aumentó de 89.000,150.000 y 59.000 toneladas a $211.000,219.000$ y 278.000 , respectivamente. En ese período la capacidad media de las industrias de Brasil y Argentina alcanzó 136.000 y 35.000 toneladas, respectivamente. Actualmente, los principales proyectos del Cono Sur están constituidos por el complejo Aldea Verde de la empresa Arauco en Chile, con una capacidad de producción 1.200.000 t/año de pasta, Montes del Plata en Uruguay, con una capacidad de 1.300.000 t/año y el complejo industrial Guaiba en Brasil, con dos líneas de producción que suman de 1.700.000 t/año (Arauco 2015; Lignum, 2017; PaperAge 2015; CMPC Celulose Riograndense, 2017). El menor resultado de Argentina con relación al resto del Cono Sur se puede explicar en la no conformación de una estrategia exportadora, consecuencia del objetivo del modelo ISI. En ese sentido, tampoco podría hacerlo en la actualidad, dada la insuficiente economía de escala de sus plantas industriales.

Del análisis de la producción y exportación de cada país, se puede postular la existencia de tres situaciones: Brasil representa un modelo dirigido tanto al mercado interno como al externo; Chile y Uruguay se enfocan a un modelo de industrialización para exportación, y Argentina sólo al mercado interno (ISI).

\section{Conclusiones y recomendaciones}

Con respecto a la hipótesis del trabajo, la evidencia empírica muestra que Argentina alcanzó prácticamente en su totalidad el autoabastecimiento en celulosa y productos de trasformación mecánica de la madera, sin alcanzar el objetivo de sustitución de importaciones de papel. Consecuentemente, es posible afirmar que las políticas y sus instrumentos de promoción fueron exitosos en relación a la industria maderera (transformación mecánica) y fracasaron en el plano celulósico papelero.

A diferencia de lo acontecido con los otros países del Cono Sur, no se consolidó un desempeño exportador sostenible en el tiempo, situación a alcanzar para lograr la evolución del ISI, ya sea a un sistema de Industrialización Orientada a la Exportación como el imperante en Chile y Uruguay o hacia un modelo de desarrollo industrial orientado tanto al crecimiento de la cadena de valor sectorial como a la inserción en los mercados internacionales, que es el caso del sector brasileño.

Con base en el análisis histórico de las políticas e instrumentos implementados, se puede expresar que Argentina durante más de siete décadas aplicó, con diferentes instrumentos de promoción sectorial, un mismo modelo conceptual que se materializó de manera similar en 
diferentes contextos locales e internacionales (ISI, globalización, apertura de la economía, MERCOSUR, entre los más relevantes): subsidiar la generación de recursos leñosos, privilegiando en buena parte de su historia el abastecimiento de la industria celulósica; objetivo no explicitado, por otro lado, en forma taxativa en la normativa vigente para cada período.

Más allá de los indicadores que se elijan (superficie forestada y/o producción y exportación de bienes), Argentina está rezagada con relación al desempeño del resto de los países comparados, no obstante haber compartido una situación similar en lo cuantitativo en la década de 1960, aún con instrumentos de promoción conceptualmente semejantes. Como se dijo, Brasil, Chile y Uruguay siempre llevaron adelante una estrategia que apuntaba a la inserción en los mercados externos.

No obstante los resultados logrados en materia de superficie forestal implantada,Argentina no ha implementado una política forestal nacional que, además de sustituir importaciones, promueva un incremento sostenido de la competitividad sistémica de las cadenas de valor conformadas por PyMES en el rubro de la transformación mecánica de la madera, con el objeto de lograr una mejora cuali-cuantitativa de su producción, de impulsar el inicio o el aumento de las exportaciones de productos de mayor valor agregado y de crear nuevos empleos, en un contexto de sustentabilidad ambiental, social y económica. Particularmente, si el análisis se concentrara exclusivamente en la coyuntura actual, la oferta potencial sustentable de madera de plantaciones forestales es superior a la demanda, circunstancia que habilita a cuestionar en cierto modo la continuidad del apoyo económico no reintegrable a la implantación de forestaciones con fines industriales. No obstante, a criterio de los autores del presente trabajo, la evaluación debe efectuarse en un contexto más global en el cual se aborde la evolución de la demanda interna y externa, la competitividad del sector y los beneficios ambientales vinculados a las plantaciones forestales.

En base al análisis efectuado se concluye que si bien ciertas condiciones macroeconómicas pueden incentivar períodos de crecimiento foresto industrial acotados en el tiempo, un desarrollo sectorial sostenido solo será posible en el marco de un proceso de planificación participativa entre el Estado y los diferentes actores del sector. En ese sentido, la experiencia adquirida permite inferir que una intervención del Estado basada exclusivamente en un instrumento de incentivo económico global -y directo para las plantaciones forestalesno es suficiente para promover el desarrollo forestal si no se acompaña de otra batería de acciones tendientes a aumentar la competitividad del sector, el incremento de la demanda de los productos de origen forestal y las exportaciones de bienes con alto valor agregado.

Los objetivos de la política a implementar deben, entonces, definir claramente si solamente se procurará acompañar el crecimiento del mercado interno o si se pretende evolucionar desde una segunda etapa del modelo ISI a alguna variante del modelo IOE materializado en una estrategia exportadora perdurable en el tiempo para el subsector celulósico papelero 
o maderero o una combinación de ambos. Si se optase por la primera alternativa, la promoción entendida en los términos actuales podría considerarse como finalizada. Por ende, debería sustituirse por nuevas variantes que potencien aquellos aspectos exitosos del anterior régimen, ahora asociados a nuevos objetivos. En ese sentido, se propone focalizar la promoción en el impulso al desarrollo local apuntando a pequeños productores y MIPyMES madereras, mediante el agregado de valor en productos y servicios provenientes de las forestaciones como dendroenergía, construcción, muebles y la producción de viviendas de madera industrializadas y sus partes (en 2018 el Estado argentino estableció como meta que el 10\% de las viviendas sociales sean de madera, tal como lo estipula la Resolución 3-E/2018 del Ministerio de Interior, Obras Públicas y Vivienda, Secretaría de Vivienda y Hábitat).

En cuanto a la estrategia exportadora, la más inmediata posibilidad (y complementaria de la anterior) es promover la inserción de productos madereros en nichos de mercado específicos (tal como sucedió a principios del presente siglo), pasando entonces a un sistema de promoción selectiva de exportaciones de alto valor agregado con impacto en el desarrollo socioeconómico regional. Este escenario se visualiza como el de acceso más factible, dadas la escala, especialización y experiencia de ciertos actores de la cadena forestoindustrial, a diferencia de los mercados de commodities a los cuales exportan Brasil, Chile y Uruguay. En este plano, los instrumentos de promoción deben ser más amplios que la sola generación del recurso maderero, incorporando instrumentos de promoción industrial tales como instrumentos impositivos, administrativos y financieros que mejoren la competitividad: estabilidad fiscal, estímulos específicos a la exportación y a la incorporación de bienes de capital, líneas de crédito blandos a largo plazo y de financiamiento de capital de trabajo, simplificación de las operatorias de importación y exportación y el mantenimiento de un tipo de cambio real competitivo a lo largo del tiempo. Por otra parte, se debe considerar la implementación de proyectos y programas orientados a incorporar a nuevos actores, impulsar el desarrollo de nuevas modalidades de articulación entre pequeños y medianos productores con los actores nacionales de mayor relevancia, con el objeto de propiciar y facilitar un posicionamiento creciente en los nichos de mercado externo, protegiendo al mismo tiempo al mercado interno.

Con relación al mercado de celulosa, la magnitud de las inversiones requeridas para convertirse en un actor competitivo en los mercados globales, solo se dará mediante el ingreso de capitales extranjeros, con el riesgo de la consecuente incorporación en una cadena cuya gobernanza y decisiones de inversión son ajenas al alcance de las políticas nacionales. En tal caso, la decisión de promover ese tipo de inversiones se encuentra fuera del marco actual de la institucionalidad forestal.

Los criterios a emplear para el diseño y aplicación de nuevos instrumentos de promoción, deberían abordar simultáneamente tres aspectos: los paradigmas que fundamentan la promoción, los instrumentos propiamente dichos y el alcance territorial de las intervenciones del Estado. Específicamente, se considera útil cambiar el paradigma de promover 
solamente el desarrollo de plantaciones forestales productoras de madera con destino industrial por otro que estimule diferentes modalidades de plantaciones que contribuyan a un desarrollo sostenible e integral de los territorios, articulando con otras actividades locales como el turismo, la ganadería y los servicios ambientales demandados por la población. En ese sentido, se deberían implementar mecanismos de promoción diferenciados para las distintas regiones con potencial forestal del país, discriminando si el destino es industrial, la generación de servicios ambientales (incluyendo el turismo) o una combinación de ellos. 
${ }^{1}$ Los biomas son grandes regiones biogeográficas que difieren de otras en la estructura de su vegetación y en sus especies vegetales dominantes (Villaseñor, 2015).

${ }^{2} \mathrm{Su}$ actual misión es promover el desarrollo tecnológico de la industria de la celulosa y el papel, y otras actividades industriales afines, a fin de mejorar la competitividad de estos sectores y favorecer su inserción en el marcado internacional de los bienes que producen.

${ }^{3}$ Los cálculos se realizaron a partir de los datos publicados en la página web de la Dirección Nacional Desarrollo Foresto Industrial, Ministerio de Agroindustria de la Nación (https://www.agroindustria.gob.ar/sitio/areas/ ss_desarrollo_foresto_industrial/estadisticas/).

${ }^{4}$ Remanufactura: producto que parte de madera ya aserrada y se transforma en insumos de otras. Ejemplo: vigas multilaminadas, tableros alistonados, ensamble tipo finger joint, molduras de madera, machimbre, entre otras.

${ }^{5}$ Una burbuja especulativa ocurre cuando un alto porcentaje de las transacciones en un mercado se realizan a precios que difieren significativamente con los valores intrínsecos de los bienes en cuestión (Byun, 2010). 


\section{Referencias bibliográficas}

Aguilar Villanueva, L. (2009). "Marco para el análisis de las políticas públicas”. En Mariñez F. y V. Garza Cantú (Coord.), Política pública y democracia en América Latina. Del análisis a la implementación. México: EGAP/CERALE/Miguel Ángel Porrúa, pp. 11-31.

Agrovoz (2017). “Negocios de buena madera: la industria forestal busca un plan para expandirse". Disponible en: http://agrovoz.lavoz.com.ar/agricultura/negocios-de-buena-maderala-industria-forestal-busca-un-plan-para-expandirse, último acceso: 21 de junio de 2018

Aguerre, M. y G. Denegri (2004). "El sector forestal y forestoindustrial en los 90. Incidencia de las inversiones externas directas en el comercio exterior". Realidad Económica 207:90-110.

Arauco (2015).Memoria anual. Disponible en:http://www.arauco.cl/_file/file_6231_16502memoria_arauco-2015.pdf, último acceso: 15 de septiembre de 2015

Argentina Forestal (2013). "Durán: Alto Paraná marca una tendencia grave con la venta de madera aserrada a bajos precios en el mercado interno". Disponible en: http:// www.argentinaforestal.com/2013/03/13/duran-alto-parana-marca-una-tendenciagrave-con-la-venta-de-madera-aserrada-a-bajos-precios-en-el-mercado-interno/, último acceso: 24 de octubre de 2015.

Audino, P. y F.Tohmé (2001). “El modelo Agro-Exportador argentino y sus descontentos: la crítica alas políticas económicas entre 1900y 1930”. Departamento de Economía Universidad Nacional del Sur. Disponible en: http://s3.amazonaws.com/academia.edu.documents/43368509/audino_tohme.pdf?AWSAccessKeyId=AKIAJ56TQJRTWSMTNPEA\&Expires=1474995651\&Signature=Zu6SQD5qU6OSoNXfYyYNFjp8e9U\%3D\&response-content-disposition =inline\%3B\%20filename\%3DEl_Modelo_Agro-Exportador_Argentino_y_su.pdf

BCRA, Banco Central de la República Argentina (2016). "Índice del Tipo de Cambio Real Multilateral Diario". Disponible en http://www.bcra.gob.ar/Pdfs/ PublicacionesEstadisticas/TCRMMetodologia.pdf, último acceso: 3 de agosto de 2015

Bercovich, N. y J. Katz (1997). Reestructuración industrial y apertura económica: La industria de celulosa y papel de Argentina, Brasil y Chile en los años 90. Buenos Aires: Alianza Editorial.

Bowyer, J. (2004). “Cambios en los mercados del sector forestal”. Unasylva: Revista internacional de silvicultura e industrias forestales (FAO). Vol. 55(219), 59-64. Disponible en http:// www.fao.org/docrep/008/y5918s/y5918s13.htm, último acceso: 30 de julio de 2018. 
Byun, K. (2010). “The U.S. housing bubble and bust:impacts on employment”. Monthly Labor Review. Bureau of Economic Analysis. December 2010, 3-17. Disponible en: https:// www.bls.gov/opub/mlr/2010/12/art1full.pdf, último acceso: 5 de noviembre de 2016 .

Carabelli, F. (2010). "Reflexiones en torno a la necesidad de más profesionales forestales en Argentina”. Serie Técnica de Extensión, (1), Facultad de Ingeniería, Sede Esquel, Universidad Nacional de la Patagonia San Juan Bosco.

Castiglioni, J. y J. Tinto (1968). Proyecto para un Plan Nacional de Forestación. Buenos Aires: Administración Nacional de Bosques, Secretaria de Estado de Agricultura y Ganadería. Series Planificación del Desarrollo Forestal (1).

Chéliz, P. (2002) “"La teoría y la práctica de la estrategia de industrialización orientada hacia la exportación”. Acciones e Investigaciones Sociales. 14:71-88. Disponible en: https:// papiro.unizar.es/ojs/index.php/ais/article/view/213, último acceso: 22 de junio de 2017.

CEPAL-ALADI (2012). "Treinta años de Integración Comercial en la ALADI". Montevideo: Documento CEPAL-ALADI.Disponible en:http://www.aladi.org/biblioteca/Publicaciones/ ALADI/Secretaria_General/Documentos_Sin_Codigos/Caja_061_004.pdf, último acceso 30 de julio de 2018.

Chéliz, P. (2002). La teoría y la práctica de la estrategia de industrialización orientada hacia la exportación. Acciones e investigaciones sociales, (14), 71-88. Disponible en:https:// dialnet.unirioja.es/servlet/articulo? codigo $=233658$

Chidiak, M. y N. Bercovich (1995). "Desarrollo y crisis de la producción de celulosa y papel en Argentina”. Santiago de Chile: Documento CEPAL. Disponible en: https://repositorio. cepal.org/bitstream/handle/11362/30373/S9501064_es.pdf?sequence=1\&isAllowed $=\mathrm{y}$ , último acceso: 30 de julio de 2018.

CMPC Celulose Riograndense (s.f) Guaiba II. Disponible en: http://www.celuloseriograndense.com.br/ último acceso: 14 de febrero de 2017.

Cortés Conde, R. (2009). The political economy of Argentina in the twentieth century. New York: Cambridge University Press.

Corporación Forestal Nacional. Ministerio de Agricultura de Chile (s.f) Nuestros bosques: Plantaciones forestales. Disponible en: http://www.conaf.cl/nuestrosbosques/plantaciones-forestales/ , último acceso: 24 de noviembre de 2017. 
De Grace, T. (2011). “The housing market crash of 2007 and what caused the crash". Disponible en: http://www.stockpickssystem.com/housing-market-crash-2007/ último acceso: 13 de diciembre de 2017.

Denegri, G. y M. Aguerre (1996).'Incidencia de las políticas de sustitución de importaciones sobre las forestaciones (1960/94)". Realidad Económica, (141):104-113.

Denegri, G. y M.Aguerre (2010). "Competitividad de la cadena del mueble de tableros en Argentina”. Observatorio de la Economía y la Sociedad Latinoamericana No 130. Disponible en: http://www.eumed.net/cursecon/ecolat/ar/ último acceso: 5 de mayo de 2017.

De negri, G., G. Acciaresi y M. Aguerre (2017). "Políticas públicas de promoción de plantaciones forestales comerciales: los casos del Valle de Calamuchita (Córdoba) y de la región de Virasoro (Corrientes)". Revista de la Facultad de Agronomía (Universidad Nacional de La Plata). 115(2): 232-245.

Denegri, G., M.Aguerre y G. Acciaresi (2016). "Caracterización del complejo productivo de la madera de la Provincia de Córdoba, Argentina. Factores que dificultan su competitividad”. Cuadernos Geográficos (Universidad de Granada). 55(1):1-18.

Denegri, G., A. Rodríguez Vagaría A., J. Mijailoff, J. Mársico y G. Acciaresi (2018). "Bosques urbanos: su aporte al turismo en la costa atlántica norte (Argentina)". Estudios y Perspectivas en Turismo (CIET - Argentina). 27(2), 316-335.

Evans, J. (2009). “The history of tree planting and planted forests". En Planted forests: uses, impacts and sustainability (5-22). Roma: FAO. Disponible en: http:// www.fao.org/forestry/24489-0e54aef5c0bee7238cf5ebd97931a4bb7.pdf, último acceso: 16 de febrero de 2018 .

FAO, Organización de las Naciones Unidas para la Alimentación y la Agricultura (2010). "Elaboración de una política forestal eficaz. Una guía”. Estudio FAO Montes 161. Disponible en: http://www.fao.org/docrep/013/i1679s/i1679s00. pdf, último acceso: 15 de febrero de 2018.

FAOSTAT (2017). Forestry production and trade. Disponible en http://www.fao.org/ faostat/en/\#data/, último acceso: 2 de marzo de 2018.

Gereffi, G. (2001). "Las cadenas productivas como marco analítico de la globalización”. Problemas del desarrollo. 125:9-37. IIEC-UNAM. México. 
Gereffi, G., J. Humphrey, R. Kaplinsky \& T. Sturgeon. (2001). "Introduction: Globalisation, value chains and development". IDS bulletin, 32(3), 1-8. Disponible en: https://www.ids.ac.uk/files/dmfile/gereffietal323.pdf, último acceso: 24 de julio de 2018.

Gereffi, G., J. Humphrey \& T. Sturgeon (2005). "The governance of global value chains". Review of international political economy, 12(1), 78-104. Disponible en: https:// rrojasdatabank.info/sturgeon2005.pdf, último acceso: 24 de julio de 2018.

Hueting, R., L. Reijnders, B. de Boer, J. Lambooy \& H. Jansen (1998). “The concept of environmental function and its valuation". Ecological Economics, 25(1), 31-36.

Ley N¹3.273 (1948). Defensa de la Riqueza forestal. Boletín oficial 16.174. República Argentina. Disponible en: http://servicios.infoleg.gob.ar/infolegInternet/verNorma. do?id=30713 | Último acceso: 24 de julio de 2018.

Ley N²5.080 (1998). Inversiones para bosques cultivados. Régimen de promoción. Boletín Oficial 29.066. República Argentina. Disponible en: http://servicios.infoleg. gob.ar/infolegInternet/verNorma.do?id=55596 | Último acceso: 24 de julio de 2018.

Ley N²6.432 (2008). Prórroga y reforma de la Ley N²5.080. Boletín Oficial 31.561. República Argentina. Disponible en: http://servicios.infoleg.gob.ar/infolegInternet/ anexos/145000-149999/148753/norma.htm | Último acceso: 24 de julio de 2018.

Lignum (2017). Celulosa: el papel clave del Mercado. Santiago: Editorial Lignum. Disponible en http://www.lignum.cl/reportajes/celulosa-papel-clave-mercado | último acceso: 20 de octubre de 2017.

Mac Donagh P., S. Berger, J. Fhaler, G. Fornaso, C. Belinger, D. Paiva y N. Bedrij (2012, octubre). "Experiencia del aglomerado productivo forestal Misiones y Corrientes Norte". Actas de las XXVI Jornadas Forestales de Entre Ríos, en CD. Concordia, Entre Ríos.

MINAGRI (Ministerio de Agroindustria). (2015). Estadísticas. Disponible en www. agroindustria.gob.ar/sitio/areas/ss_desarrollo_foresto_industrial/estadisticas/_archivos//000000_Comercio Exterior/150000_Resumen de las transacciones de productores forestales 2015.pdf, último acceso: 15 de marzo de 2018.

Misiones Online (2013) "La venta de madera aserrada de Alto Paraná en el mercado interno perjudica a las PyMES forestales misioneras”. Marzo. Disponible en: http:// misionesonline.net/2013/03/05/la-venta-de-madera-aserrada-de-alto-paran-en-elmercado-interno-perjudica-a-las-pymes- forestales-misioneras/, último acceso: 20 de octubre de 2017. 
Misiones Online (2014). "Bajaron la-producción y las ventas del sector maderero en el primer semestre del año”.Junio. Disponible en: http://misionesonline.net/2014/06/11/ bajaron-la-produccion-y-las-ventas-del-sector-maderero-en-el-primer-semestre-delano/ último acceso: 20 de octubre de 2017.

OKFN, Open Knowledge International (2016). U.S. Housing Price Index (Case Schiller index). Cambridge, UK. Disponible en: http://data.okfn.org/data/core/houseprices-us, Ùltimo acceso: 15 de diciembre de 2016.

PaperAge (2015).“CMPCStarts-up New PulpLine2at Guaiba MillinBrazil”.Disponible en: http://www.paperage.com/2015news/05_06_2015cmpc_guaiba_start_up.html

Prado Donoso, J. (2015). "Plantaciones Forestales. Más Allá de los Árboles”. Santiago de Chile: Colegio de Ingenieros Forestales. Disponible en: http://www.corma.cl/_file/material/plantaciones-forestales-mas-alla-de-los-arboles_-j.pdf, último acceso: 12 de diciembre de 2017.

Rougier, M. (2007). Políticas de promoción y estrategias empresariales en la industria argentina 1950-1980. Buenos Aires: Ediciones Cooperativas.

Sautu, R. (2004). Todo es teoría. Objetivos y métodos de investigación. Buenos Aires: Editorial Lumiére.

Schlichter T., D. Díaz, J. Fahler y P. Laclau (2012). Aportes a una política forestal en Argentina: El sector forestal y el desarrollo económico, ambiental y social del país. Buenos Aires: Ministerio de Agricultura, Ganadería y Pesca. MAGyP. Unidad para el Cambio Rural, UCAR. Disponible en: http://www.ucar.gob.ar/images/publicaciones/Aportes $\% 20$ a\%20una \%20pol\%C3\%ADtica\%20forestal\%20argentina $\% 20$ en $\% 20$ el $\% 20$ siglo $\% 20$ XXI.pdf, último acceso: 1 de agosto de 2017.

SERFOR, Servicio nacional forestal y de fauna silvestre (2018). Servicios forestales/ Plantaciones forestales. Disponible en: https://www.serfor.gob.pe/bosques-productivos/servicios-forestales/plantaciones-forestales, último acceso: 19 de febrero de 2018.

Sforzi, Fabio (2008). “Unas realidades ignoradas. De Marshall a Becattini”. Mediterráneo Económico. ISSN 1698-3726. 13, 43-54, Disponible en https://dialnet.unirioja.es/ servlet/articulo? codigo $=2602187$

Sikkink, K. (2009). El proyecto desarrollista en la Argentina y Brasil: Frondizi y Kubitschek. Buenos Aires: Siglo Veintiuno. 
Vaccarezza, F. (2010). Políticas de desarrollo industrial en la Argentina 1940-200. Desde la sustitución a la apertura. Buenos Aires: Centro Argentino de Estudios Internacionales.

Vasilachis de Gialdino, I. (1992). Métodos cualitativos. I Los problemas teórico- epistemológicos. Buenos Aires: Centro Editor de América Latina.

Villaseñor, J. (2015). “¿La crisis de la biodiversidad es la crisis de la taxonomía?”. Botanical Sciences, 93(1), 03-14. Disponible en http://www.scielo.org.mx/scielo. php?script $=$ sci_arttext\&pid $=$ S2007-42982015000100002\&lng $=$ es\&nrm $=$ iso, último acceso: 31 de julio de 2018 .

\section{Cómo citar este artículo:}

Aguerre, Martín, Gerardo Denegri y Gustavo Acciaresi (2019): "Políticas de promoción sectorial en Argentina: el caso de las plantaciones forestales y la conformación del sector forestoindustrial”. Revista Perspectivas de Políticas Públicas vol. 8 No16:329-363 